\title{
Experimental and theoretical investigation of spontaneous and surface-enhanced Raman scattering (SERS) spectroscopy of pure and boron-doped carbon nanotubes
}

\author{
H. Hasan Bouzari ${ }^{1} \cdot$ L. Farhang Matin ${ }^{1} \cdot$ R. Malekfar $^{2} \cdot$ A. Shafiekhani ${ }^{3}$
}

Received: 26 February 2018 / Accepted: 14 June 2018/Published online: 9 July 2018

(c) The Author(s) 2018

\begin{abstract}
In this paper, due to the importance and abundant applications of carbon nanotubes doped with boron $\left(\mathrm{CNT} / \mathrm{B}_{2} \mathrm{O}_{3}\right)$ in various industries with changes in the electrical, mechanical and chemical properties, mode identification and intensity of the Raman spectra of pure and boron oxide molecule-doped spectra have been performed. The main task in this paper is to monitor the alteration of the relevant vibrational mode intensities of the pure and B-doped samples. In experimental approach, by utilizing a simple method we synthesized CNT doped with $\mathrm{B}_{2} \mathrm{O}_{3}$ using laser ablation in liquid environment technique. The silver nanoparticles were made by the Lee-Meisel method, and then the spontaneous and surface-enhanced Raman scattering (SERS) spectra of pure and B-doped carbon nanotubes were collected. In simulation approach, using the Gauss View and Gaussian software [basis set 6-31G, computational method DFT (B3LYP)], the spontaneous and SERS spectroscopy of pure and B-doped carbon nanotubes was calculated. Due to the presence of silver nanoparticles in the vicinity of carbon nanotube and boron element, SERS intensity to spontaneous Raman (NR) intensity ratio $\left(I_{\mathrm{SERS}} / I_{\mathrm{NR}}\right)$ increases in the $D, G$ and boron oxide modes of up to 12 -fold were observed. A good agreement is found between the computational and the experimental SERS results for the vibrational spectra of the synthesized composite materials.
\end{abstract}

Keywords Raman spectroscopy · Carbon nanotubes · Boron · Doping · SERS

\section{Introduction}

Carbon nanotubes (CNTs) have become very interesting systems due to their unique structural and electronic properties as well as their diverse applications [1]. Since the discovery by Iijima and Ichihashi, CNTs have drawn great attention due to their superior properties such as high surface area and chemical stability [2]. The surface of CNTs congregates more negative charges and has been actively and widely studied [3]. Historically, CNTs have

L. Farhang Matin

laleh.matin@gmail.com

1 Department of Physics, North Tehran Branch, Islamic Azad University, Tehran, Islamic Republic of Iran

2 Departments of Physics, Faculty of Basic Sciences, Tarbiat Modares University, Tehran, Islamic Republic of Iran

3 Department of Physics, Faculty of Physics and Chemistry, Alzahra University, Tehran, Islamic Republic of Iran acted as probe molecule to be used in sensitive Raman test and study about the interfacial reactions between CNTs and metallic support for their unique electronic features, high aspect ratio and strong electron-phonon coupling [4]. Doping of carbon nanotubes was first attempted by Stephan et al. in 1994; they synthesized boron-doped CNTs using arc-discharge method [5]. Raman spectroscopy shows that boron doping of CNTs converted their chemical and optical properties [6]. It has been shown that boron doping in nanotubes gives rise to a prominent acceptor strip near the Fermi level, and as a result the nanotubes are plentiful in holes. Therefore, the presence of the acceptor band ensures that the boron-doped CNTs display permanent $p$-type character [7].

Detecting single molecules and identifying their chemical structures are among the main scopes of increased interest. The observation of spectroscopic signals at the single molecule level is the main scientific advantage, as it provides insight into the intrinsic properties of a molecule 
[8]. Fluorescence microscopy is used as a touchy and single molecule spectroscopic tool which deals detecting single molecules by fluorescence and it must be demonstrated by fluorescent dye molecules to get high enough fluorescence quantum yields and detectable spectral properties [9]. However, in SERS technique, fluorescence is a disturbing process and with some experimental techniques, this problem should be resolved. In SERS when the target molecule is joined to noble metallic nanoparticles (e.g., Ag, $\mathrm{Cu}, \mathrm{Au}, . .$.$) , the Raman signal can be enhanced up to more$ than tenfold of magnitude $[10,11]$. Silver nanoparticles are the only metal whose plasmon resonance can be adapted to any wavelength in the visible spectrum $[12,13]$. Flemish in 1974 used harsh Ag electrode surface to record the first SERS spectrum [14]. The technique of SERS can be applied for obtaining the materials structural and identification information in low concentrations [15]. In this article, for confirming the high SERS activity of Ag NPs, the B-CNTs composite has been chosen as a probe because it has been well characterized by SERS and most of the prominent Raman bands have been assigned. For explaining the enhanced mechanism of SERS, it is now generally accepted that there are two interacting clarifications, which explain the origin of SERS effect: electromagnetic [16] and chemical effects [17]. The cross sections of spontaneous Raman scattering $\left(\sim 10^{-30} \mathrm{~cm}^{-2}\right)$ are much smaller than that of IR absorption $\left(\sim 10^{-19} \mathrm{~cm}^{-2}\right)$ or fluorescence $\left(\sim 10^{-16} \mathrm{~cm}^{-2}\right)$. Therefore, signal enhancement technique is very useful for Raman scattering measurements. Raman scattering from molecules adsorbed on metallic nanostructures is strongly enhanced due to the excitation of localized surface plasmon polaritons. This phenomenon is known as surface-enhanced Raman scattering (SERS), the enhancement factor of which has been reported to reach up to $10^{5}-10^{20}$ [18]. The organization of this article is as follows: (1) a new method for introducing boron oxide $\left(\mathrm{B}_{2} \mathrm{O}_{3}\right)$ molecule to the carbon nanotubes lattice structure with laser ablation in a liquid environment (LALE) will be explained. (2) Silver nanoparticles (Ag NPs) will be fabricated via Lee-Meisel method. (3) Spontaneous and SERS spectra of pure and B-doped carbon nanotubes will be presented by experimental and simulation methods. (4) Finally, the results of the experimentally recorded spontaneous and SERS Raman spectra will be compared by the relevant spectra obtained by the simulation method.

\section{Materials and methods}

\section{Preparation and SEM imaging of $\mathrm{CNT} / \mathrm{B}_{2} \mathrm{O}_{3}$}

The carbon nanotubes (CNTs) (diameter $\sim 15-20 \mathrm{~nm}$; length $\sim 2.5 \mu \mathrm{m}$ ) were prepared by CVD method grown on $\mathrm{Ni}$ catalyst at $660{ }^{\circ} \mathrm{C}$ for $20 \mathrm{~min}$. The $\mathrm{CNT} / \mathrm{B}_{2} \mathrm{O}_{3}$ was prepared by using laser ablation method using the fundamental wavelength of a Ce-doped $\mathrm{Nd} / \mathrm{YAG}$ laser at $1064 \mathrm{~nm}$. First, pure CNTs powder was mixed with boron oxide $\left(\mathrm{B}_{2} \mathrm{O}_{3}\right)$, with a ratio of $97: 3 \mathrm{wt} \%$, respectively. Then, the sample was treated in ethanol solution and the suspending liquid using laser beam $(80 \mathrm{~mJ})$ for $15 \mathrm{~min}$. The mixture solution was heated and stirred during laser irradiation. The sample was dispersed under ultra-sonication technique for $10 \mathrm{~min}$ to produce uniformed $\mathrm{CNT} / \mathrm{B}_{2} \mathrm{O}_{3}$. The resulting material is shown in Fig. 1 in a representative SEM image of doped CNTs $\left(C N T / \mathrm{B}_{2} \mathrm{O}_{3}\right)$. The scale bar is $200 \mathrm{~nm}$.

\section{Preparation of Ag NPs}

Ag NPs because of their ability in exhibiting localized surface Plasmon resonances (LSPR) have found many applications in bio-detection LSPR excitation can considerably enhance the local electric field which is the main reported mechanism of surface-enhanced Raman spectroscopy (SERS) [19]. A variety of methods for the synthesis of Ag NPs has been reported in the scientific literature. This preparation is simple, but great care must be exercised to make stable and reproducible colloids. The wet chemical syntheses can produce nano-sized colloids in many different shapes [20]. The processes can be divided into two categories (traditional and non-traditional). The traditional methods are the solution-phase synthesis techniques that are based on different modifications of the LeeMeisel method, and there are a series of examples in which

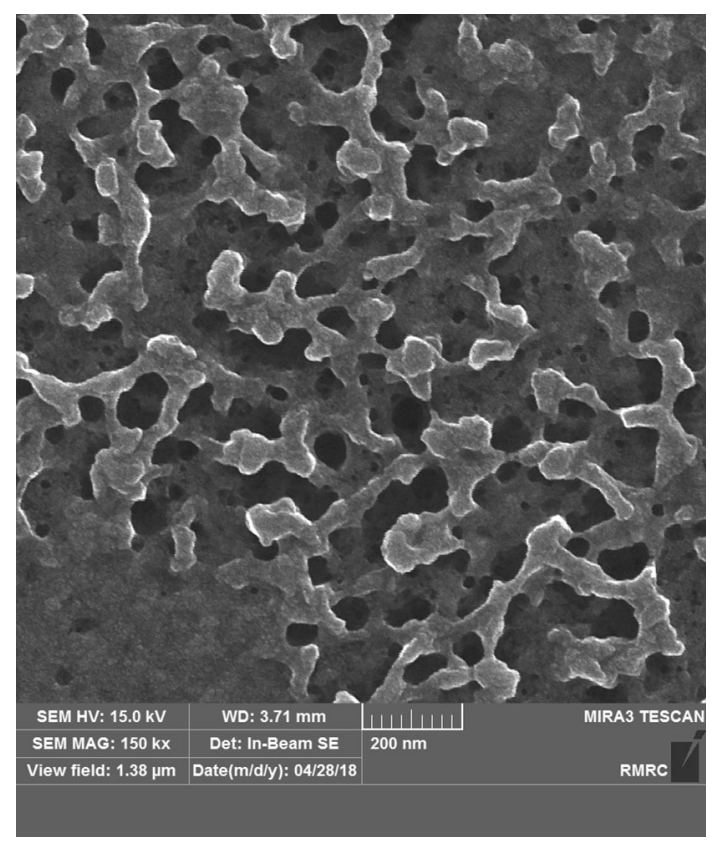

Fig. 1 SEM image of doped CNTs $\left(\mathrm{CNT} / \mathrm{B}_{2} \mathrm{O}_{3}\right)$ 
Fig. 2 UV/Vis/NIR absorption spectrum of the Ag NPs synthesized by the Lee-Meisel method

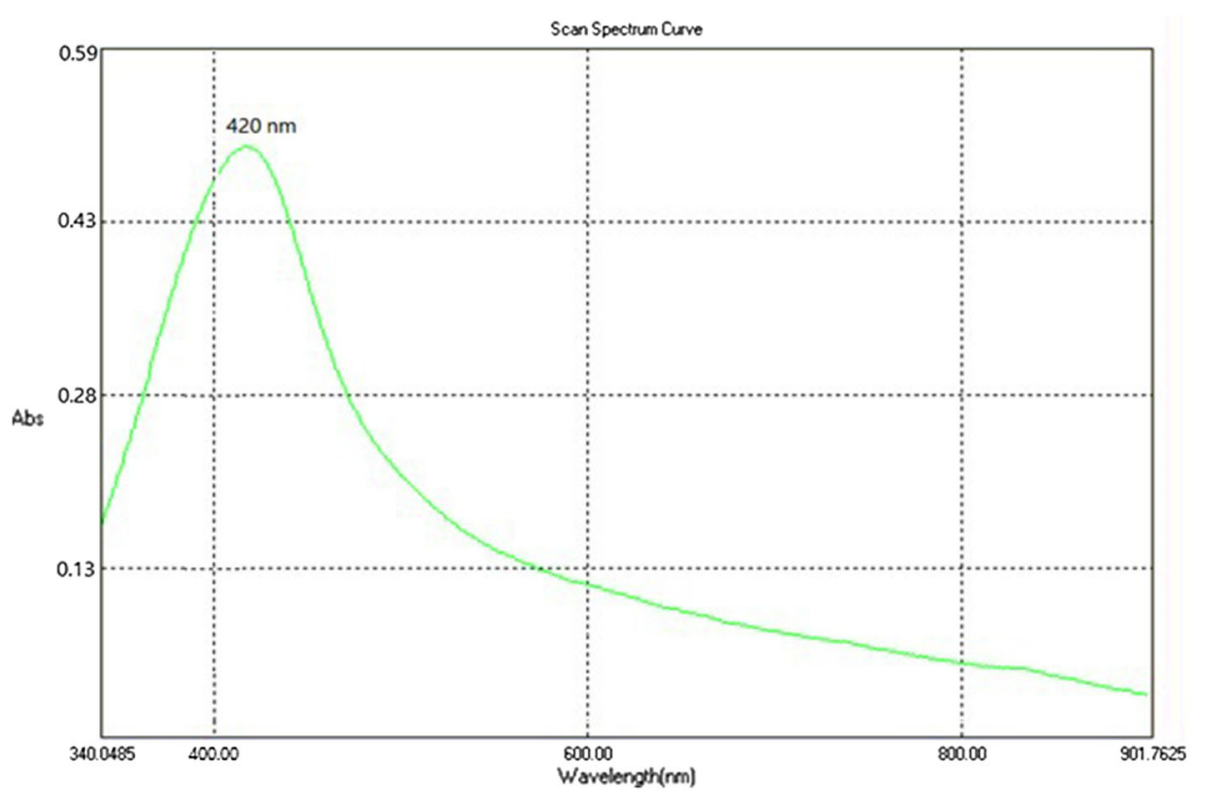

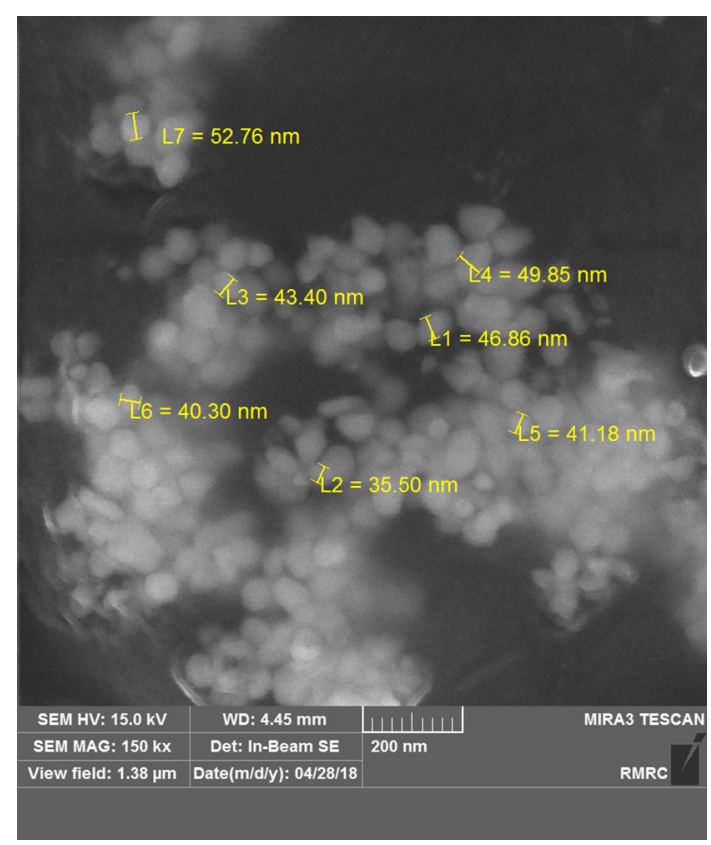

Fig. 3 SEM image of the Ag NPs synthesized by the Lee-Meisel method

different $\mathrm{Ag}$ salts and reducing factors are used [12, 13]. The non-traditional methods include vapor-phase condensation of a metal onto a solid support [21-23], laser ablation of a metal target into a suspending liquid [24], photoreduction of $\mathrm{Ag}$ ions [25, 26] and electrolysis of an Ag salt solution [27, 28]. With the solution-phase synthesis techniques, the main problem is a limited flexibility in the size of particles that can be produced. For Ag NPs suspensions, a common method is the Lee-Meisel method, which is a variation of the Turkevich method in which $\mathrm{AgNO}_{3}$ is used as the metal source [29].

In this work, silver nanoparticles were prepared using the Lee-Meisel method. $\mathrm{AgNO}_{3}(17 \mathrm{mg}$ ) was dissolved in $100 \mathrm{~mL}$ of deionized water and brought to boiling. A solution of $1 \mathrm{wt} \%$ sodium citrate $(7 \mathrm{~mL})$ was added to the reaction solution. The solution was kept on boiling for $8 \mathrm{~min}$ and cooled to room temperature.

The chemical reaction of the process is as follows:

$$
\begin{aligned}
& \quad 4 \mathrm{Ag}^{+}+\mathrm{C}_{6} \mathrm{H}_{5} \mathrm{O}_{7} \mathrm{Na}_{3}+2 \mathrm{H}_{2} \mathrm{O} \\
& \stackrel{\rightarrow}{\rightarrow} \mathrm{Ag}+\mathrm{C}_{6} \mathrm{H}_{5} \mathrm{O}_{7} \mathrm{H}_{3}+3 \mathrm{Na}^{+}+\mathrm{O}_{2} .
\end{aligned}
$$

\section{Results and discussion}

\section{Experimental section}

\section{Absorption spectroscopy and SEM imaging of Ag NPs}

Ultraviolet-visible-near infrared (UV/Vis/NIR) spectroscopy refers to absorption or reflectance spectroscopy in this region of electromagnetic waves. This means it uses light in the visible and adjacent ranges. The absorption or reflectance in the visible range has direct impacts on the perceived color of the chemicals involved. Absorption spectroscopy is complementary to fluorescence spectroscopy, in that fluorescence deals with transitions from the excited state to the ground state, while absorption gauges transitions from the ground state to the excited state [30]. UV/Vis/NIR absorption spectroscopy was used to 


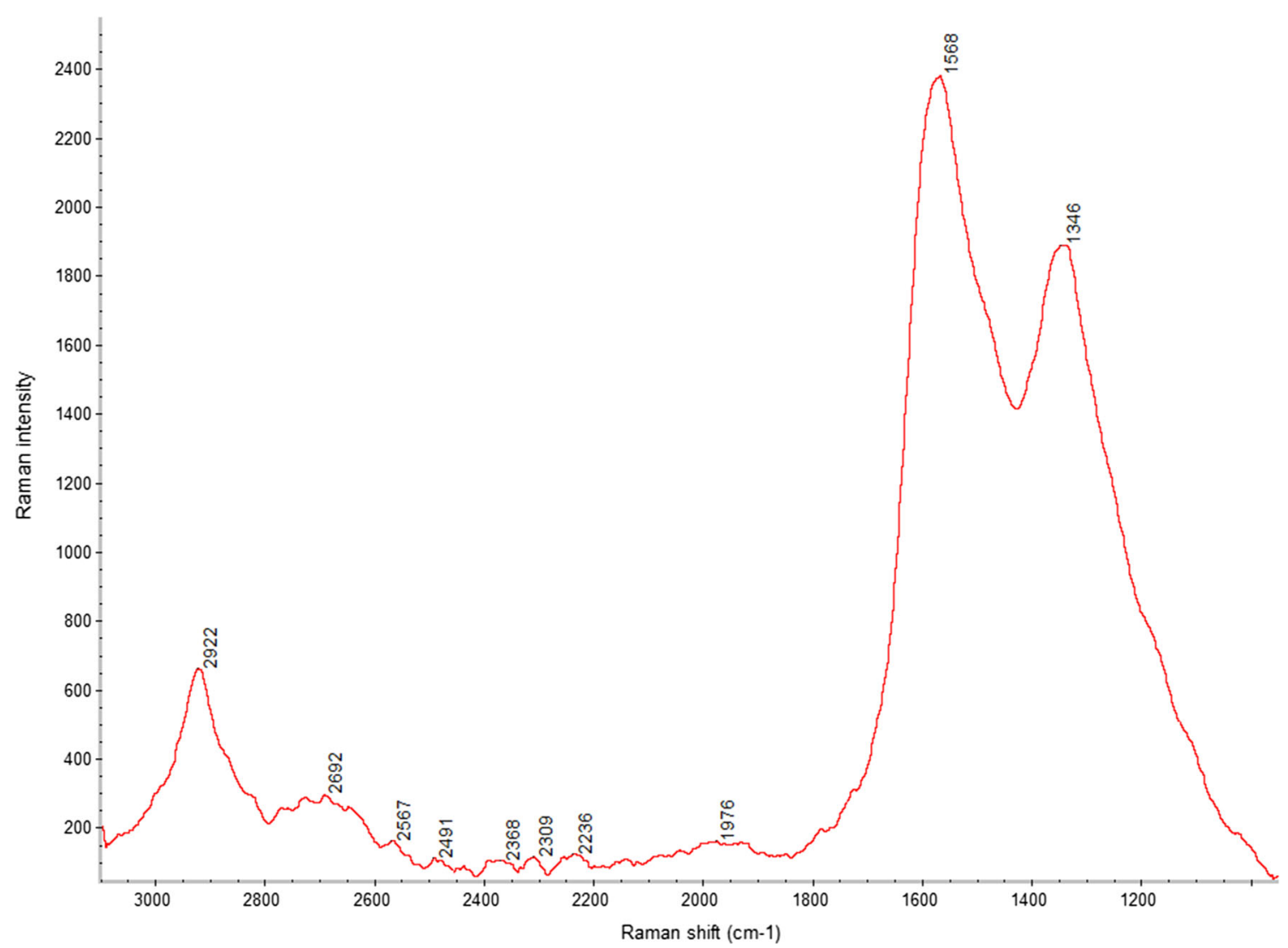

Fig. 4 Raman spectrum of CNT synthesized by CVD method

provide further insight into the interaction among ground state electrons within the hybrid structures [31].

The localized surface plasmon resonance (LSPR) of Ag nanoparticles is illustrated in the UV/Vis/NIR absorption spectra collected by UV/Vis/NIR spectrometer manufactured by $\mathrm{T} 80+\mathrm{PG}$ Instruments, and a typical spectrum is shown in Fig. 2. There is an absorption peak at $\sim 420 \mathrm{~nm}$ for Ag NPs.

By increasing the size of the silver nanoparticles, the absorption spectrum shifts to higher wavelengths. The observed spectral shift results from the distributing of the particles surface charge upon a larger surface area so that the surrounding medium make up better the restoring force thus slowing the electron oscillations [32]. According to the absorption spectrum obtained from silver nanoparticles $(420 \mathrm{~nm})$, the synthesized nanoparticles have an average grain size of around $50 \mathrm{~nm}$ [33].

SEM image of Ag NPs is shown in Fig. 3, and the average sizes of the Ag NPs are around $50 \mathrm{~nm}$. The scale bar is $200 \mathrm{~nm}$.

\section{Raman spectroscopy of CNT}

Raman spectroscopy was used to investigate the crystallinity and the structural changes of carbon framework of
CNTs. To perform Raman spectroscopy, Almega Dispersive Raman spectrometer system manufactured by Thermo Nicolet with the second harmonic of a Nd/YLF laser beam with a wavelength of $532 \mathrm{~nm}$ was used. As shown in Fig. 4, the CNTs sample shows prominent peaks at $1346 \mathrm{~cm}^{-1}$ ( $D$ band) and also a peak at $1568 \mathrm{~cm}^{-1}$ ( $G$ band). The intensity of the vibrating $D$ mode (which shows the presence of deformation, impurities and amorphous carbons in the carbon nanotubes) and the intensity of the vibrating $G$ mode (which displays the existence of the order in the carbon network) were examined. The $D$ band represents edges, other defects and disordered carbon due to the vibration of $s p^{3}$-bonded carbon atoms and impurities, whereas the $\mathrm{G}$ band arises from the zone center $E_{2 \mathrm{~g}}$ mode, assigning to the ordered $s p^{2}$-bonded $C$ atoms [34].

The Raman intensity of $D$ and $G$ peaks of CNT powder is 1800 (a.u.) and 2400 (a.u.), respectively. The degree of crystallinity in carbon samples was evaluated using the $D$ $G$ band intensity $\left(I_{\mathrm{D}} / I_{\mathrm{G}}\right)$ ratio, which is the intensity of the disorder mode at $D$ band divided by the intensity of graphite mode at $\mathrm{G}$ band. As shown in Fig. 4, due to the purity of the sample, the intensity of the Raman spectrum of $\left(I_{\mathrm{D}} /\right.$ $\left.I_{\mathrm{G}}\right)$ ratio is less than one. 


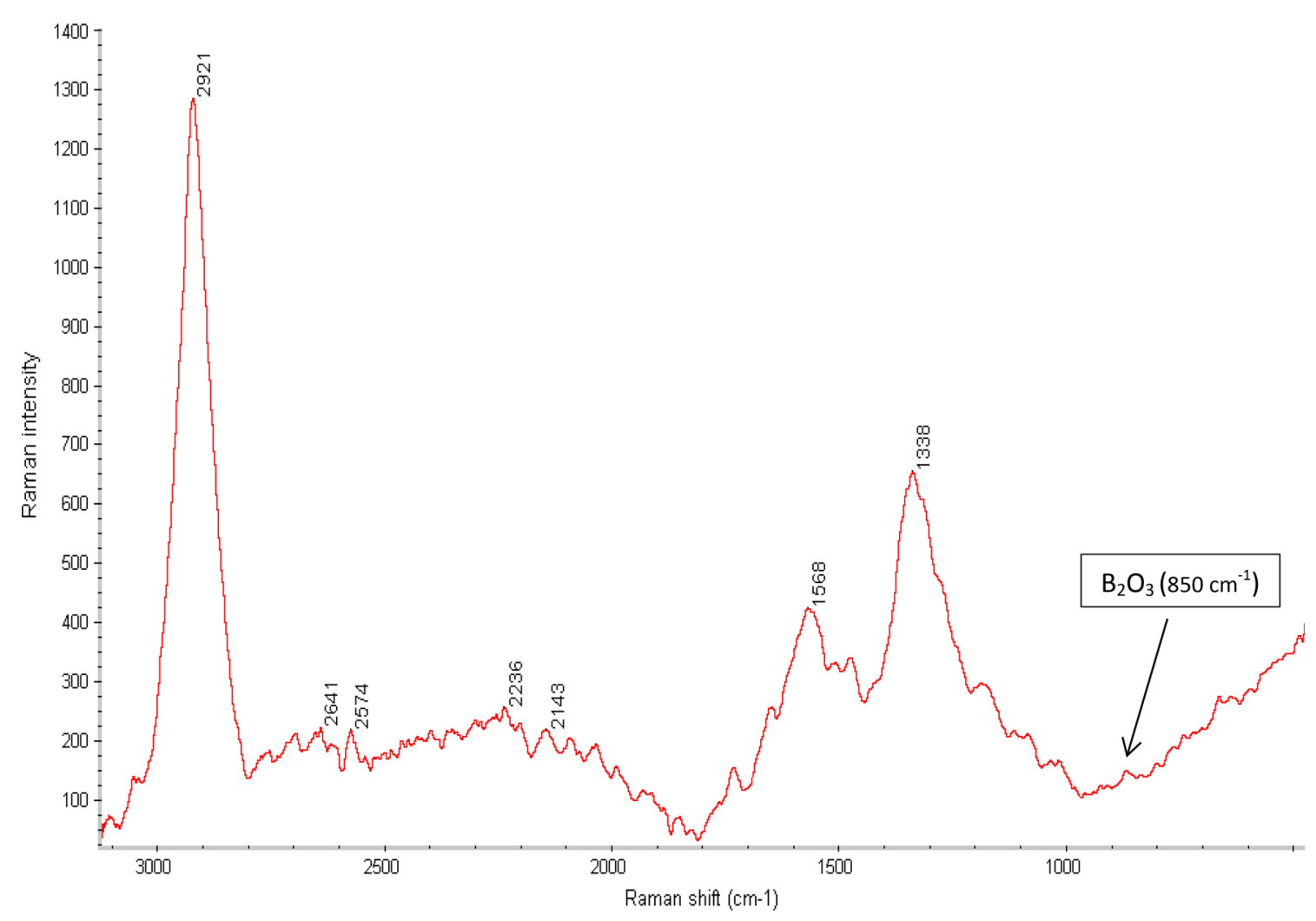

Fig. 5 Raman spectrum of $\mathrm{CNT} / \mathrm{B}_{2} \mathrm{O}_{3}$

$$
\begin{aligned}
& \left(I_{\mathrm{D}}\right)_{\mathrm{N}}=1800 \text { (a.u.) } \\
& \left(I_{\mathrm{G}}\right)_{\mathrm{N}}=2400 \text { (a.u.) } \\
& \frac{I_{\mathrm{D}}}{I_{\mathrm{G}}}=\frac{1800}{2400}=0.75
\end{aligned}
$$

\section{Raman spectroscopy of $\mathrm{CNT} / \mathrm{B}_{2} \mathrm{O}_{3}$}

The predominant band in the spectrum of $\mathrm{B}_{2} \mathrm{O}_{3}$ is located at $850 \mathrm{~cm}^{-1}$ [35-37]. As shown in Fig. 5, the Raman intensity of $D$ and $G$ peaks of CNTs/ $\mathrm{B}_{2} \mathrm{O}_{3}$ is at around 700 (a.u.) and 450 (a.u.), respectively. The $I_{\mathrm{D}} / I_{\mathrm{G}}$ ratio after introducing $\mathrm{B}_{2} \mathrm{O}_{3}$ is higher than that of pure CNTs, which can be related to the doping effect

$$
\begin{aligned}
& \left(I_{\mathrm{D}}\right)_{\mathrm{N}}=700 \text { (a.u.) } \\
& \left(I_{\mathrm{G}}\right)_{\mathrm{N}}=450 \text { (a.u.) } \\
& \left(I_{\mathrm{B}_{2} \mathrm{O}_{3}}\right)_{\mathrm{N}}=125 \text { (a.u.) } \\
& \frac{I_{\mathrm{D}}}{I_{\mathrm{G}}}=\frac{700}{450}=1.5
\end{aligned}
$$

Increasing $I_{\mathrm{D}} / I_{\mathrm{G}}$ value from 0.75 to 1.5 suggests a decrease in in-plane size of graphene upon the reduction process [38]. It can be seen that the Raman intensity of vibrational mode at $850 \mathrm{~cm}^{-1}$ (corresponding to the $\mathrm{B}_{2} \mathrm{O}_{3}$ ) is 125 (a.u.).

\section{Raman enhancement of $\mathrm{CNT} / \mathrm{B}_{2} \mathrm{O}_{3}-\mathrm{Ag} \mathrm{NPs}$}

In this section, we have compared the Raman intensities of $\mathrm{CNT} / \mathrm{B}_{2} \mathrm{O}_{3}, \mathrm{CNT} / \mathrm{B}_{2} \mathrm{O}_{3}-\mathrm{Ag}$ NPs. As shown in Fig. 6, we can see that the Raman intensity of $\mathrm{CNT} / \mathrm{B}_{2} \mathrm{O}_{3}-\mathrm{Ag}$ NPs is larger than that of $\mathrm{CNT} / \mathrm{B}_{2} \mathrm{O}_{3}$. For Raman peak position at $850 \mathrm{~cm}^{-1}\left(\mathrm{~B}_{2} \mathrm{O}_{3}\right)$, the Raman intensity of $\mathrm{B}_{2} \mathrm{O}_{3}$ is about 125 (a.u.) and for $\mathrm{B}_{2} \mathrm{O}_{3}-\mathrm{Ag}$ NPs is about 2400 (a.u.). The reason can be considered due to the intensity enhancement by Ag NPs.

$$
\begin{aligned}
& \left(I_{\mathrm{D}}\right)_{\mathrm{SERS}}=9000 \text { (a.u.) } \\
& \left(I_{\mathrm{G}}\right)_{\mathrm{SERS}}=3500 \text { (a.u.) } \\
& \left(I_{\mathrm{B}_{2} \mathrm{O}_{3}}\right)_{\mathrm{SERS}}=2400 \text { (a.u.) }
\end{aligned}
$$

The SERS enhancement factor (EF) has been defined [39]:EF $=\frac{I_{\text {SERS }}}{I_{\text {Normal }}} \times \frac{V_{\text {Normal }}}{V_{\text {SERS }}} \times \frac{C_{\text {Normal }}}{C_{\text {SERS }}}$, where $I_{\text {SERS }}$ and $I_{\text {Normal }}$ are the peak intensity on $\mathrm{CNT} / \mathrm{B}_{2} \mathrm{O}_{3}-\mathrm{Ag} \mathrm{NPs}$ and $\mathrm{CNT} /$ $\mathrm{B}_{2} \mathrm{O}_{3}$, respectively; $V_{\text {SERS }}$ and $V_{\text {Normal }}$ are the probe volumes for the $\mathrm{CNT} / \mathrm{B}_{2} \mathrm{O}_{3}-\mathrm{Ag}$ NPs and $\mathrm{CNT} / \mathrm{B}_{2} \mathrm{O}_{3}$ measurements, respectively; and $C_{\mathrm{SERS}}$ and $C_{\text {Normal }}$ are the $\mathrm{CNT} / \mathrm{B}_{2} \mathrm{O}_{3}$ concentrations that contribute to SERS (I $I_{\text {SERS }}$ ) 


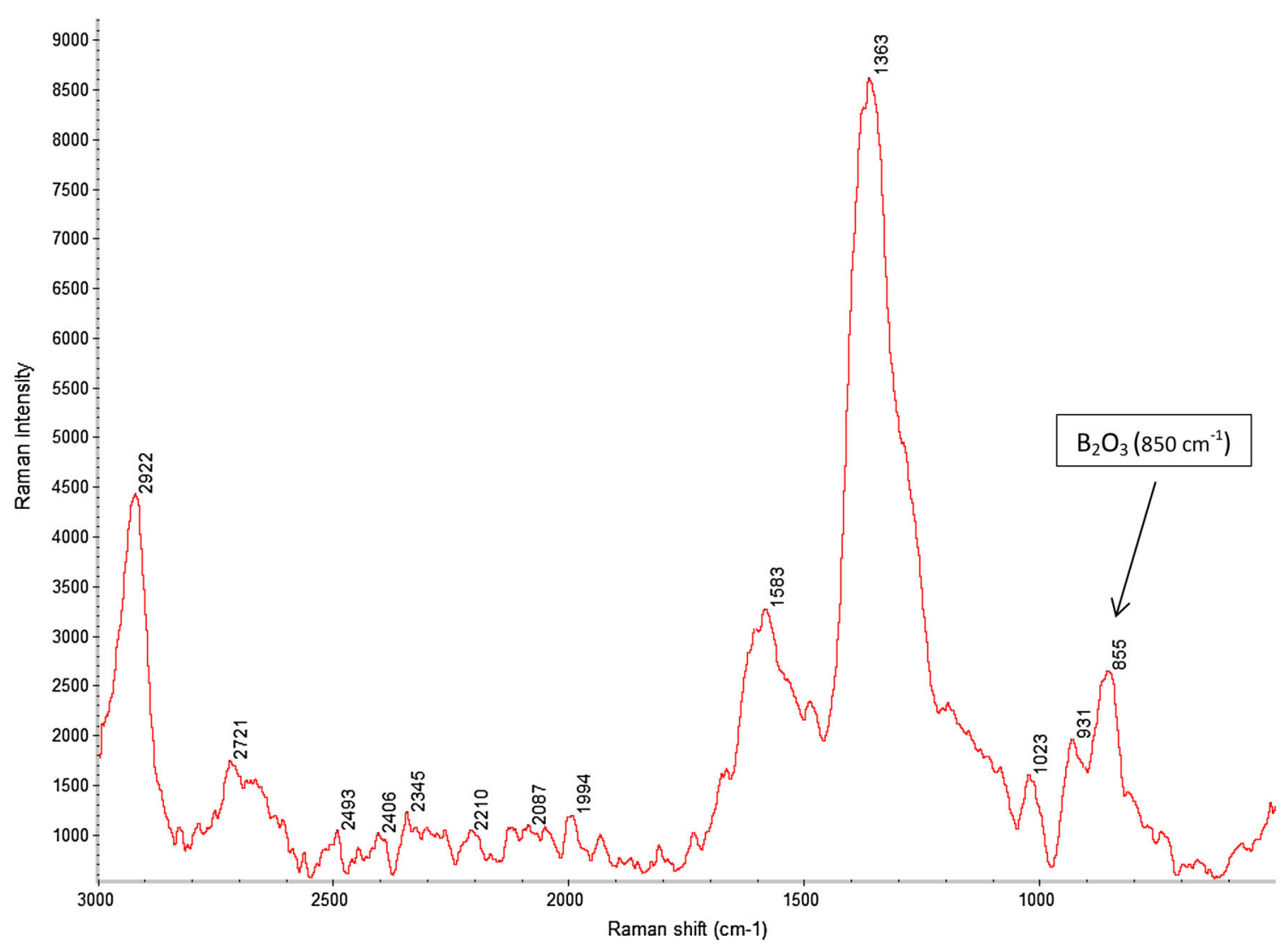

Fig. 6 Raman spectrum of $\mathrm{CNT} / \mathrm{B}_{2} \mathrm{O}_{3}-\mathrm{Ag} \mathrm{NPs}$
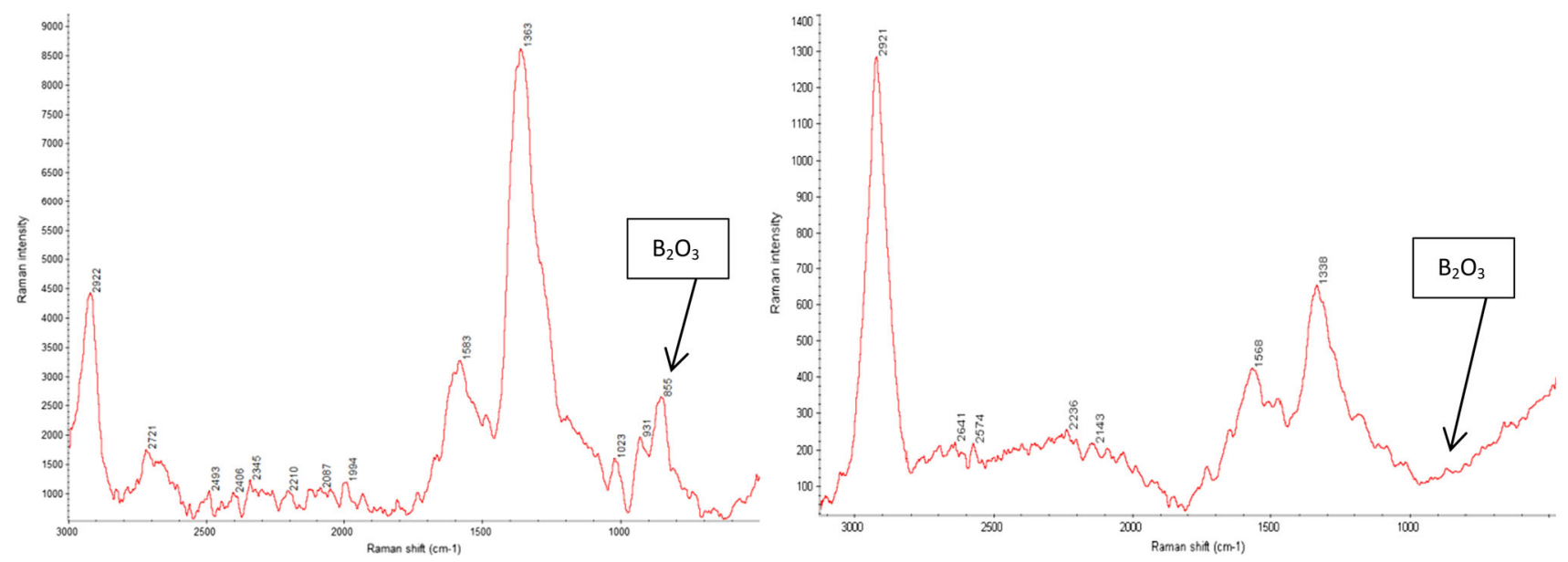

Fig. 7 A comparison between SERS, left, and spontaneous Raman, right, spectra presented in Figs. 5 and 6

Table $1 I_{\mathrm{D}}, I_{\mathrm{G}}$ and $I_{\mathrm{B}_{2} \mathrm{O}_{3}}$ of CNT, CNT/B $\mathrm{B}_{2} \mathrm{O}_{3}$ and $\mathrm{CNT} / \mathrm{B}_{2} \mathrm{O}_{3}-\mathrm{Ag} \mathrm{NPs}$ samples from the spectra presented in Figs. 2, 3 and 4

\begin{tabular}{llll}
\hline Intensity & \multicolumn{2}{l}{ Samples } & \\
\cline { 2 - 4 } & $\mathrm{CNT}$ & $\mathrm{CNT} / \mathrm{B}_{2} \mathrm{O}_{3}$ & $\mathrm{CNT} / \mathrm{B}_{2} \mathrm{O}_{3}-\mathrm{Ag} \mathrm{NPs}$ \\
\hline$I_{\mathrm{B}_{2} \mathrm{O}_{3}}$ & - & 125 & 2400 \\
$I_{\mathrm{D}}$ & 1800 & 700 & 9000 \\
$I_{\mathrm{G}}$ & 2400 & 400 & 3500 \\
\hline
\end{tabular}

and normal Raman intensities $\left(I_{\text {Normal }}\right)$, respectively (Fig. 7).

For $D, G$ and $\mathrm{B}_{2} \mathrm{O}_{3}$ peaks, the $\mathrm{EF}$ is:

$$
\begin{aligned}
(\mathrm{EF})_{\mathrm{D}} & =\frac{I_{\text {SERS }}}{I_{\text {Normal }}} \times \frac{V_{\text {Normal }}}{V_{\text {SERS }}} \times \frac{C_{\text {Normal }}}{C_{\text {SERS }}}=\frac{9000}{700} \times 1 \times 1 \\
& =12.8
\end{aligned}
$$



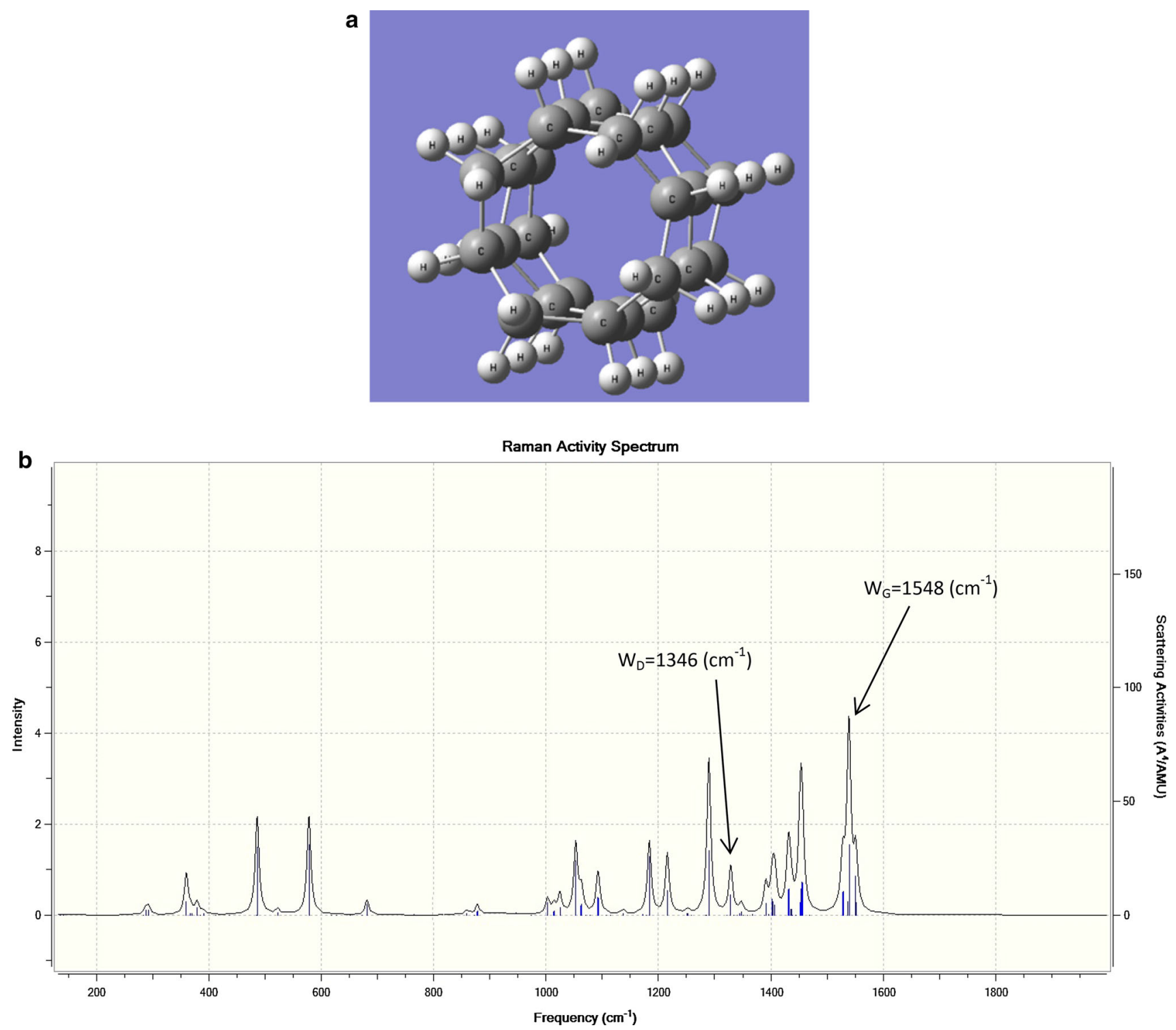

Fig. 8 a Schematic illustration of CNT structure. b Theoretical calculation of Raman spectrum of CNT

$(\mathrm{EF})_{\mathrm{G}}=\frac{I_{\text {SERS }}}{I_{\text {Normal }}} \times \frac{V_{\text {Normal }}}{V_{\text {SERS }}} \times \frac{C_{\text {Normal }}}{C_{\text {SERS }}}=\frac{3500}{400} \times 1 \times 1=8.8$

$(\mathrm{EF})_{\mathrm{B}_{2} \mathrm{O}_{3}}=\frac{I_{\text {SERS }}}{I_{\text {Normal }}} \times \frac{V_{\text {Normal }}}{V_{\text {SERS }}} \times \frac{C_{\text {Normal }}}{C_{\text {SERS }}}=\frac{2400}{125} \times 1 \times 1$

$$
=19.2
$$

The synthesis of Ag NPs can be used as a stable suspension for the production of enhanced Raman signals for up to 1 month. The intensity of the SERS signals is enhanced by up to 12 -fold. The enhancement can be related to the concentration of Ag NPs and the molarity of two probe molecules [40]. The $I_{\mathrm{B} 2 \mathrm{O} 3}, I_{\mathrm{D}}$ and $I_{\mathrm{G}}$ of CNT, CNT/ $\mathrm{B}_{2} \mathrm{O}_{3}$ and $\mathrm{CNT} / \mathrm{B}_{2} \mathrm{O}_{3}-\mathrm{Ag}$ NPs samples are summarized in Table 1.

\section{Simulation section}

In the simulation approach, using Hyperchem, Gauss View and Gaussian software was drawn pure CNT, boron-doped CNT and CNT/boron-Ag NPs. Then, the Raman spectra were obtained using the DFT (density functional theory) and B3LYP (Becke-Style three-parameter) computing methods and the 6-31G base set.

\section{Raman spectroscopy of CNT}

The schematic illustration and Raman spectrum of pure carbon nanotube are presented in Fig. 8a, b, respectively.

The Raman intensity of $D$ and $G$ peaks of CNT is 18 (a.u.) and 80 (a.u.), respectively. As can be seen, due to the 

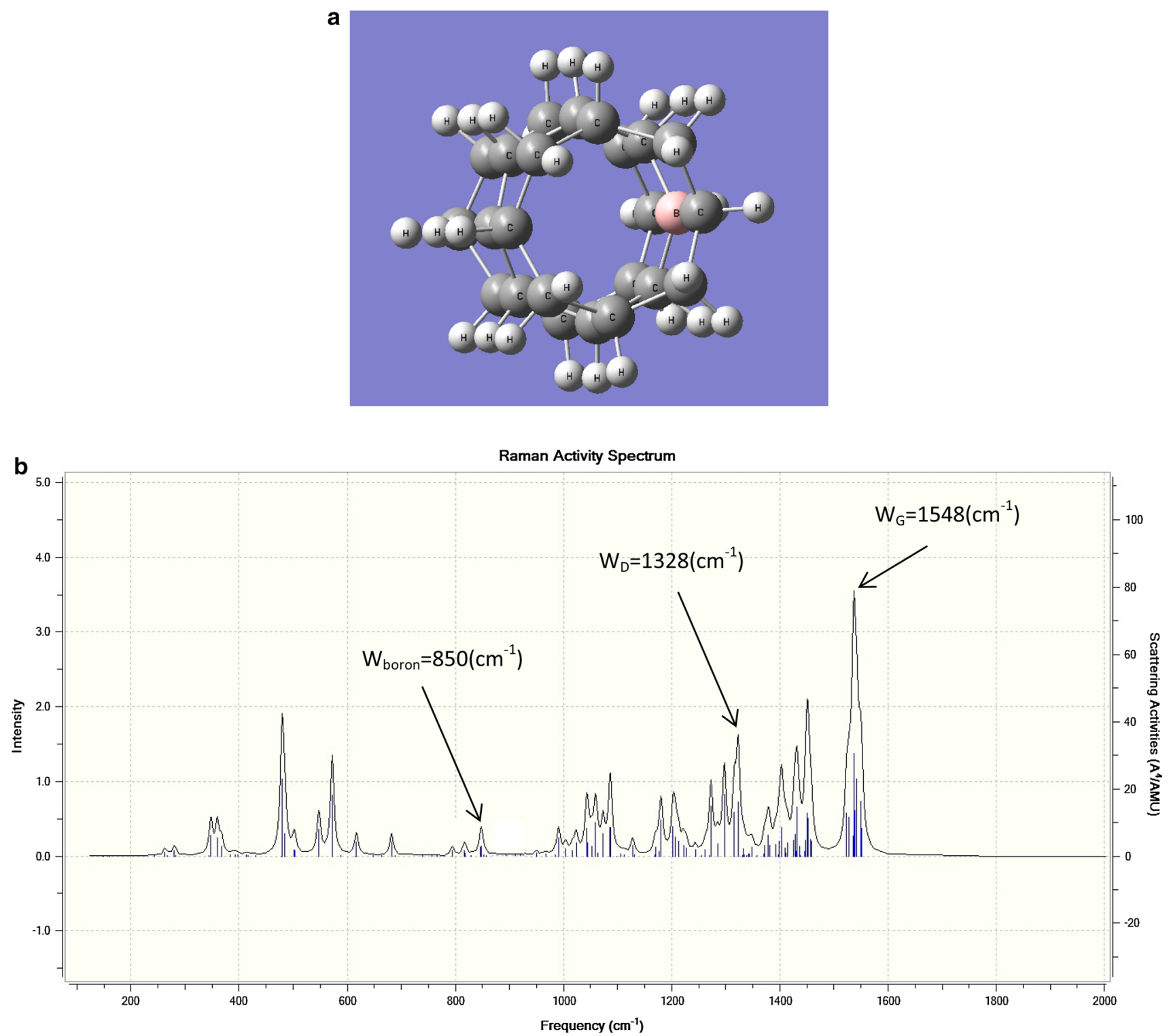

Fig. 9 a Schematic illustration of boron-doped CNT. b Theoretical calculation of Raman spectrum of boron-doped CNT

purity of the sample, the intensity of the Raman spectrum of $\left(I_{\mathrm{D}} / I_{\mathrm{G}}\right)$ ratio is less than one.

$$
\begin{aligned}
& \left(I_{\mathrm{D}}\right)_{\mathrm{N}}=18 \text { (a.u.) } \\
& \left(I_{\mathrm{G}}\right)_{\mathrm{N}}=80 \text { (a.u.) } \\
& \frac{I_{\mathrm{D}}}{I_{\mathrm{G}}}=\frac{18}{80}=0.22
\end{aligned}
$$

$$
\begin{aligned}
& \left(I_{\mathrm{D}}\right)_{\mathrm{N}}=38 \text { (a.u.) } \\
& \left(I_{\mathrm{G}}\right)_{\mathrm{N}}=78 \text { (a.u.) } \\
& \left(I_{\text {Boron }}\right)_{\mathrm{N}}=8 \text { (a.u.) } \\
& \frac{I_{\mathrm{D}}}{I_{\mathrm{G}}}=\frac{38}{78}=0.48
\end{aligned}
$$

\section{Raman spectroscopy of CNT/boron}

The schematic illustration and the Raman spectrum of boron-doped carbon nanotube are shown in Fig. 9a, b, respectively.

The Raman intensity of $D, G$ and boron peaks CNT are 38 (a.u.), 78 (a.u.) and 8 (a.u.), respectively. As can be seen, due to boron-doped CNT, the intensity of the Raman spectrum of $\left(I_{\mathrm{D}} / I_{\mathrm{G}}\right)$ ratio has increased. 

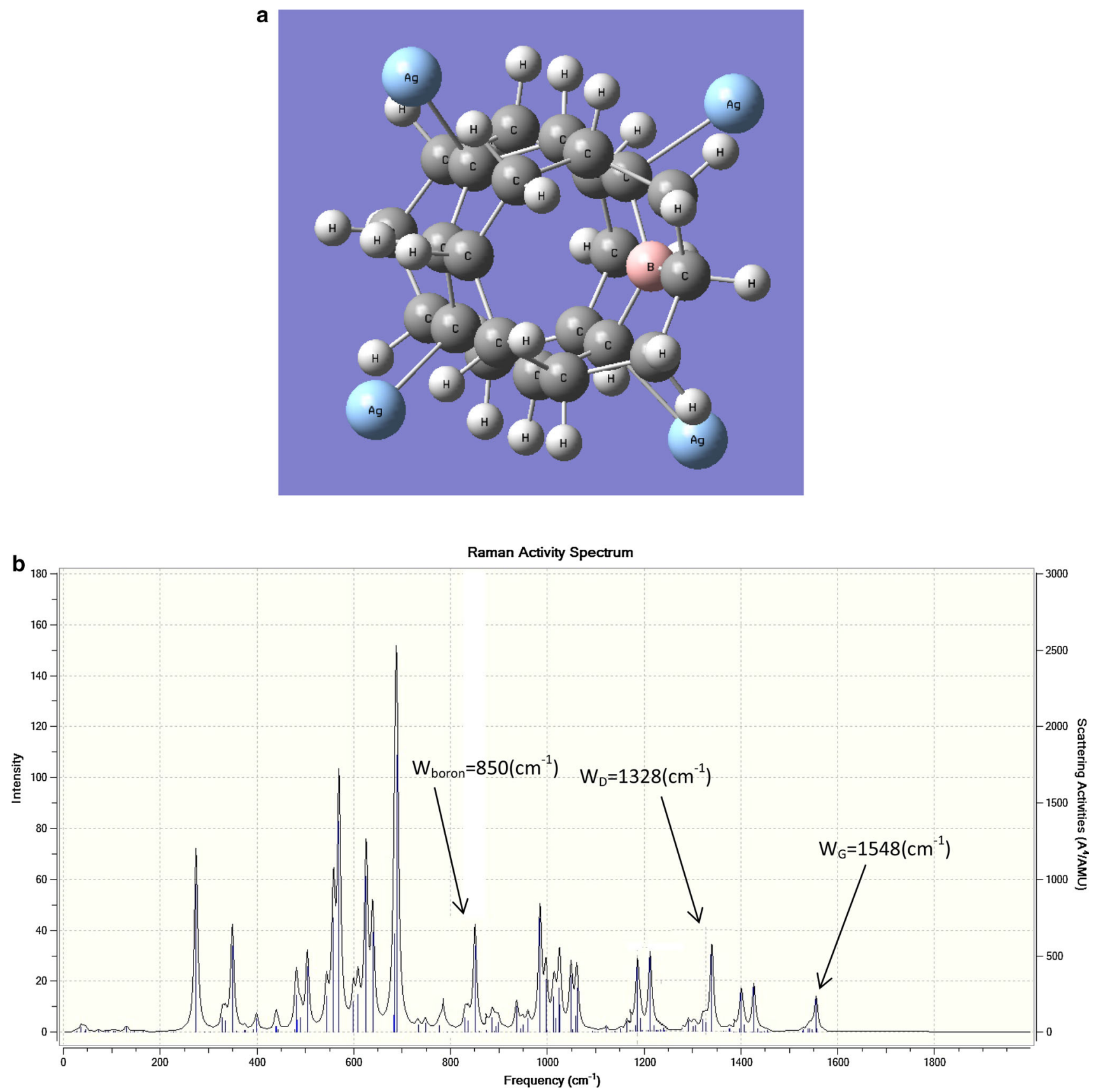

Fig. 10 a Schematic illustration of CNT/boron-Ag NPs. b Theoretical calculation of Raman spectrum of CNT/boron-Ag NPs

Table 2 The simulated intensities for $I_{\text {boron }}, I_{\mathrm{D}}$ and $I_{\mathrm{G}}$ of CNT, CNT/ boron and CNT/boron-Ag NPs samples from the spectra in Figs. 8, 9 and 10

\begin{tabular}{llll}
\hline Intensity & \multicolumn{2}{l}{ Samples } & \\
\cline { 2 - 4 } & CNT & CNT/boron & CNT/boron-Ag NPs \\
\hline$I_{\text {boron }}$ & - & 8 & 520 \\
$I_{\mathrm{D}}$ & 18 & 38 & 510 \\
$I_{\mathrm{G}}$ & 80 & 78 & 250 \\
\hline
\end{tabular}

Table 3 The comparison of the enhancement factor (EF) for boron oxide and also for the $D$ and $G$ modes results for the experimental and the simulation approaches

\begin{tabular}{llll}
\hline EF & Modes & & \\
\cline { 2 - 4 } & Boron oxide & $D$ & $G$ \\
\hline Experimental results & 12 & 12.8 & 8.8 \\
Simulation approach & 65 & 13 & 3.2 \\
\hline
\end{tabular}




\section{Raman enhancement of CNT/boron-Ag NPs}

The schematic illustration and Raman spectrum of CNT/ boron-Ag NPs are shown in Fig. 10a, b, respectively.

$$
\begin{aligned}
& \left(I_{\mathrm{D}}\right)_{\mathrm{SERS}}=510 \text { (a.u.) } \\
& \left(I_{\mathrm{G}}\right)_{\mathrm{SERS}}=250 \text { (a.u.) } \\
& \left(I_{\text {Boron }}\right)_{\mathrm{SERS}}=520 \text { (a.u.) }
\end{aligned}
$$

The Raman intensity of $D, G$ and boron peaks CNT are 510 (a.u.), 250 (a.u.) and 520 (a.u.), respectively. Ag NPs created a multitude of hot spots, with a strong SERS effect. The Raman scattering of CNT/boron has been enhanced as a result of a strongly enhanced electric field due to the presence of Ag NPs [41].

$$
\begin{aligned}
& (\mathrm{EF})_{\mathrm{D}}=\frac{I_{\text {SERS }}}{I_{\text {Normal }}} \times \frac{V_{\text {Normal }}}{V_{\text {SERS }}} \times \frac{C_{\text {Normal }}}{C_{\text {SERS }}}=\frac{510}{38} \times 1 \times 1=13 \\
& (\mathrm{EF})_{\mathrm{G}}=\frac{I_{\text {SERS }}}{I_{\text {Normal }}} \times \frac{V_{\text {Normal }}}{V_{\text {SERS }}} \times \frac{C_{\text {Normal }}}{C_{\text {SERS }}}=\frac{250}{78} \times 1 \times 1=3.2 \\
& (\mathrm{EF})_{\text {Boron }}=\frac{I_{\text {SERS }}}{I_{\text {Normal }}} \times \frac{V_{\text {Normal }}}{V_{\text {SERS }}} \times \frac{C_{\text {Normal }}}{C_{\text {SERS }}}=\frac{520}{8} \times 1 \times 1 \\
& =65
\end{aligned}
$$

The simulation results of the intensities for $I_{\text {boron }}, I_{\mathrm{D}}$ and $I_{\mathrm{G}}$ of CNT, CNT/boron and CNT/boron-Ag NPs samples are summarized in Table 2.

Table 3 shows the comparison between the results of the experimental and the simulation methods.

\section{Conclusions}

In this article, a facile procedure to synthesize $\mathrm{CNT} / \mathrm{B}_{2} \mathrm{O}_{3}$ hybrid and its spontaneous Raman and the signal enhancement at Ag nanostructured surface using SERS has been presented.

The increase in the Raman signal intensity (for experimental and simulation approaches) reveals the usefulness and effectiveness of the SERS method for detecting specific molecules with low concentrations in a matrix environment on the surface of Ag NPs. In order to compare the obtained EFs, it is also possible to use other noble metallic nanoparticles such as gold, copper and titanium to enhance the Raman signal.

Open Access This article is distributed under the terms of the Creative Commons Attribution 4.0 International License (http://creative commons.org/licenses/by/4.0/), which permits unrestricted use, distribution, and reproduction in any medium, provided you give appropriate credit to the original author(s) and the source, provide a link to the Creative Commons license, and indicate if changes were made.

\section{References}

1. Khan, M.S., Khan, M.S.: A DFT study of interaction of hydrogen molecules and $(5,5)$ carbon nanotube with bioinspired functionalization. J. Theor. Appl. Phys. 7(1), 56 (2013)

2. Kim, J.D., Yun, H., Kim, G.C., Lee, C.W., Choi, H.C.: Antibacterial activity and reusability of CNT-Ag and GO-Ag nanocomposite. Appl. Surf. Sci. 283, 227-233 (2013)

3. Iijima, S., Ichihashi, T.: Single-shell carbon nanotubes of 1-nm diameter. Nature 363, 603 (1993)

4. Tong, L.M., Li, Z.P., Zhu, T., Xu, H.X., Liu, Z.F.: Single goldnanoparticle-enhanced Raman scattering of individual singlewalled carbon nanotubes via atomic force microscope manipulation. J. Phys. Chem. C 112, 7119 (2008)

5. Stephan, O., Ajayan, P.M., Colliex, C., Redlich, P., Lambert, J.M., Bernier, P., Lefin, P.: Doping graphitic and carbon nanotube structures with boron and nitrogen. Science 266, 1683 (1994)

6. Li, L.-J., Glerup, M., Khlobystov, A.N., Wiltshire, J.G., Sauvajol, J.-L., Taylor, R.A., Nicholas, R.J.: The effects of nitrogen and boron doping on the optical emission and diameters of singlewalled carbon nanotubes. Carbon 44, 2752 (2006)

7. Carroll, D.L., Ajayan, P.M., Curran, S.: Local electronic structure in ordered aggregates of carbon nanotubes: scanning tunneling microscopy/scanning tunneling spectroscopy study. J. Mater. Res. 13, 2389-2395 (1998)

8. Rigler, R., Orrit, M., Basche, T. (eds.): Single Molecule Spectroscopy, Nobel Conference Lectures. Springer, Heidelberg (2002)

9. Michalet, X., Weiss, S.C.R.: Single-molecule spectroscopy and microscopy. Physique 3, 619-644 (2002)

10. Kneipp, K., Wang, Y., Kneipp, H., Itzkan, I., Dasari, R.R., Feld, M.S.: Population pumping of excited vibrational states by spontaneous surface-enhanced raman scattering. Phys. Rev. Lett. 76, 2444 (1996)

11. Zhang, J., Zhang, X., Chen, S., Gong, T., Zhu, Y.: Surface-enhanced Raman scattering properties of multi-walled carbon nanotubes arrays-Ag nanoparticles. Carbon 100, 395-407 (2016)

12. Evanoff Jr., D.D., Chumanov, G.: Size-controlled synthesis of nanoparticles. 2. Measurement of extinction, scattering, and absorption cross sections. J. Phys. Chem. B 108, 13957-13962 (2004)

13. Kelly, K.L., Coronado, E., Zhao, L.L., Schatz, G.C.: The optical properties of metal nanoparticles: the influence of size, shape, and dielectric environment. J. Phys. Chem. B 107, 668-677 (2003)

14. Fleischmann, M., Hendra, P.J., McQuillan, A.J.: Raman spectrum of pyridine adsorbed at a silver electrode. Chem. Phys. Lett. 26(2), 163-166 (1974)

15. Kreibig, U., Vollmer, M.: Properties of Metal Clusters, p. 25. Springer, Berlin (1995)

16. Moskovits, M.: Surface-enhanced spectroscopy. Rev. Mod. Phys. 57, 783 (1985)

17. Otto, A.: The 'chemical'(electronic) contribution to surface-enhanced Raman scattering. J. Raman Spectrosc. 36, 497 (2005)

18. Saito, Y., Verma, P.: Imaging and spectroscopy through plasmonic nano-probe. Eur. Phys. J. Appl. Phys. 46, 20101 (2009)

19. Savaloni, H., Haydari-Nasab, F., Abbas-Rohollahi, A.: Antibacterial effect, structural characterization, and some applications of silver chiral nano-flower sculptured thin films. J. Theor. Appl. Phys. 9(3), 193-200 (2015)

20. Naderi, S., Ghaderi, A., Solaymani, S., Golzan, M.M.: Structural, optical and thermal properties of silver colloidal nanoparticles. Eur. Phys. J. Appl. Phys. 58, 20401 (2012)

21. Malynych, S.Z., Chumanov, G.: Vacuum deposition of silver island films on chemically modified surfaces. J. Vac. Sci. Technol. A 21, 723-727 (2003) 
22. Zhao, Y.-P., Ye, D.-X., Wang, G.-C., Lu, T.-M.: Novel nanocolumn and nano-flower arrays by glancing angle deposition. Nano Lett. 2, 351-354 (2002)

23. Jensen, T.R., Malinsky, M.D., Haynes, C.L., Van Duyne, R.P.: Nanosphere lithography: tunable localized surface plasmon resonance spectra of silver nanoparticles. J. Phys. Chem. B 104, 10549-10556 (2000)

24. MafunV, F., Kohno, J.-Y., Takeda, Y., Kondow, T., Sawabe, H.: Structure and stability of silver nanoparticles in aqueous solution produced by laser ablation. J. Phys. Chem. B 104, 8333-8337 (2000)

25. Abid, J.P., Wark, A.W., Brevet, P.F., Girault, H.H.: Preparation of silver nanoparticles in solution from a silver salt by laser irradiation. Chem. Commun. 7, 792-793 (2002)

26. Huang, H.H., Ni, X.P., Loy, G.L., Chew, C.H., Tan, K.L., Loh, F.C., Deng, J.F., Xu, G.Q.: Photochemical formation of silver nanoparticles in poly (N-vinylpyrrolidone). Langmuir 12, 909-912 (1996)

27. Kotov, N.A., Zaniquelli, M.E.D., Meldrum, F.C., Fendler, J.H.: Two-dimensional silver electrocrystallization under monolayers spread on aqueous silver nitrate. Langmuir 9, 3710-3716 (1993)

28. Zhu, J., Liu, S., Palchik, O., Koltypin, Y., Gedanken, A.: Shapecontrolled synthesis of silver nanoparticles by pulse sonoelectrochemical methods. Langmuir 16, 6396-6399 (2000)

29. Lee, P.C., Meisel, D.J.: Adsorption and surface-enhanced Raman of dyes on silver and gold sols. Phys. Chem. 86, 3391-3395 (1982)

30. Skoog, D.A., Holler, F.J., Crouch, S.R.: Principles of Instrumental Analysis, 6th edn, pp. 169-173. Thomson Brooks/Cole, Belmont (2007). ISBN 9780495012016

31. Laurent, J.S., Voisin, C., Cassabois, G., Delalande, C., Roussignol, P., Jost, O., et al.: Ultrafast carrier dynamics in single-wall carbon nanotubes. Phys. Rev. Lett. 90(5), 404 (2003)

32. Kreibig, U., Vollmer, M.: Optical Properties of Metal Clusters, Springer Series in Materials Science 25. (a) p. 50; (b) p. 24; (c) pp. 45-46; (d) pp. 32-35; (e) p. 13. Springer, New York (1995)
33. Evanoff Jr., D.D., Chumanov, G.: Synthesis and optical properties of silver nanoparticles and arrays. ChemPhysChem 6(7), 1221-1231 (2005)

34. Das, M.R., Sarma, R.K., Saikia, R., Kale, V.S., Shelke, M.V., Sengupta, P.: Synthesis of silver nanoparticles in an aqueous suspension of graphene oxide sheets and its antimicrobial activity. Colloids Surf. B 83(1), 16-22 (2011)

35. Galeener, F.L., Lucovsky, G., Mikkelsen Jr., J.C.: Vibrational spectra and structure of pure vitreous $\mathrm{B}_{2} \mathrm{O}_{3}$. Am. Phys. Soc. Phys. Rev. B 22(8), 3983-3990 (1980)

36. Osipova L.M., Osipov A.A., Bykov V.N.: Structure of $\mathrm{B}_{2} \mathrm{O}_{3}$ Melt by Raman Spectroscopy. Institute of Mineralogy RAS, Ural Branch, Miass, Russia

37. Surovtsev, N.V., Batalov, A.E., Novikov, V.N., Ramos, M.A., Rössler, E.: Inelastic light scattering in B2O3 glasses with different thermal histories. The Journal of Chemical Physics 113(14), 5891-5900 (2000)

38. Lan, N.T., Chi, D.T., Dinh, N.X., et al.: Photochemical decoration of silver nanoparticles on graphene oxide nanosheets and their optical characterization. J. Alloys Compd. 615, 843-848 (2014)

39. Zhao, D.Y., Liu, X., Lei, D.Y., Chai, Y.: Effects of surface roughness of $\mathrm{Ag}$ thin films on surface-enhanced Raman spectroscopy of graphene: spatial nonlocality and physisorption strain. Nanoscale 6(3), 1311-1317 (2014)

40. Sun, Y.D., Han, Z.Z., Liu, H.L., He, S.N., Yang, L.B., Liu, J.H.: Three-dimensional hotspots in evaporating nanoparticle sols for ultrahigh Raman scattering: solid-liquid interface effects. Nanoscale 7(15), 6619-6626 (2015)

41. Kreibig, U., Vollmer, M.: Properties of Metal Clusters, Springer Series in Metal Science, p. 25. Springer, Berlin (1995)

Publisher's Note Springer Nature remains neutral with regard to jurisdictional claims in published maps and institutional affiliations. 